\title{
Evaluation the pattern of adverse drug reactions by non-steroidal anti- inflammatory drugs at the outpatient orthopedics department of a university teaching hospital in north India
}

\author{
Harpreet Singh Sidhu*, Akshay Sadhotra
}

Department of Pharmacology,

M.M. Institute of Medical

Sciences and Research, Ambala, Haryana, India

Received: 23 July 2018

Accepted: 30 August 2018

*Correspondence to:

Dr. Harpreet Singh Sidhu,

Email: drharry5000@

hotmail.com

Copyright: () the author(s), publisher and licensee Medip Academy. This is an openaccess article distributed under the terms of the Creative Commons Attribution NonCommercial License, which permits unrestricted noncommercial use, distribution, and reproduction in any medium, provided the original work is properly cited.

\begin{abstract}
Background: The study was conducted with an aim to evaluate the pattern of occurrence of adverse drug reactions (ADRs) of Non-steroidal anti-inflammatory drugs (NSAIDs) in orthopedic patients in a tertiary care teaching hospital of North India.

Methods: An observational study was carried out in the orthopedic outpatient department at the tertiary care hospital for the period of six months. All patients diagnosed with acute pain and receiving NSAIDs were included. The documented ADRs were assessed for causality, severity and preventability using Naranjo's algorithm and WHO-UMC scale, modified Hartwig and Seigel Scale and modified Schumock and Thornton scale, respectively.

Results: A total of 84 ADRs were reported from 51 patients. The most common ADRs observed were from gastrointestinal (38\%) followed by skin (18\%) and autonomic nervous system (12\%). Maximum number of ADRs were reported in patients on diclofenac (47\%) followed by piroxicam (44\%). Upon causality assessment, majority of the reactions were possible (61.5\% with WHO-UMC scale, and $57.1 \%$ with Naranjo's algorithm). The association of results between the two scales was statistically significant $(\mathrm{p}<0.001)$. Majority of ADRs $(73.4 \%)$ were assessed as mild and $66.7 \%$ of the ADRs were probably preventable.

Conclusions: Authors conclude that incidence of ADRs can be decreased and compliance can be improved by early detection and management.
\end{abstract}

Keywords: Adverse drug reactions, Fixed dose combination, India, Pharmacovigilance

\section{INTRODUCTION}

Pain is the one of the most common symptoms for which patients attending orthopedic out-patient department (OPD) worldwide. Pain relief is essential to improve quality of life for these patients. The management of pain in these patients, however, is a clinical challenge to physicians and a source of considerable concern among physicians. Various types of analgesics can be used in the treatment of pain.

The prescription of the proper type of analgesics is important to relieve pain more effectively and avoid unnecessary adverse events.
First line drugs for the management of acute pain are nonsteroidal anti-inflammatory drugs (NSAIDs), tramadol and tapentadol. ${ }^{1,2}$ NSAIDs do not cause sedation and are not addicting, and, therefore, these over-the-counter drugs are widely used for pain management in India. ${ }^{3}$ NSAIDs account for around $70 \%$ of the total prescriptions for orthopedic conditions. When there is inadequate relief of pain with an NSAID alone, fixed-dose combinations (FDCs) of two NSAIDs are frequently prescribed. However, the use of FDCs of two drugs with same mechanism of action is not considered rational as such FDCs increase the risk of toxicity and drug-related costs. ${ }^{4,5}$ To provide better pain relief, combination treatment with drugs with different mechanism of actions should be used 
(e.g. diclofenac + tramadol). Strong opioids like morphine and codeine; because of misuse and diversion for illicit purposes, are regulated and controlled under the narcotic drugs and psychotropic substances act of India. ${ }^{6}$ All the effective drugs used for the treatment of pain, no matter how competently used, may cause adverse drug reactions (ADRs). World Health Organization (WHO) defines an ADR as "A response to a drug which is noxious and unintended, and which occurs at doses normally used in man for the prophylaxis, diagnosis, or therapy of disease, or for the modifications of physiological function.? Pharmacovigilance (PV) is the pharmacological science relating to the collection, detection, assessment, monitoring and prevention of adverse effects or any other drug-related problem. $^{8}$ It describes the process for monitoring and evaluating ADRs. It is a key component of effective drug regulation systems, clinical practice and public health programs. Thus, a continuous monitoring of ADRs during post-marketing phase is essential. Early detection of drug toxicity helps in timely treatment of the patient, improves compliance and decreased cost of therapy.

The aim of present study was to determine the pattern of ADRs occurring in the patients with pain attending outpatient departments of orthopedic at Ambala, North India, which is a tertiary care hospital attached with the M.M. University. The ADRs were also accessed for their causality, severity and preventability.

Ethical approval was granted by the Institutional Ethics Committee of Maharishi Markandeshwar University of Medical Sciences (Approval Number: IEC/MMIMSR/16/223).

\section{METHODS}

The study was a prospective study, carried out in the orthopedic OPD of M.M. Institute of Medical Sciences and Research Hospital, Ambala, North India for a period of 6 months from December 2014 to 31st May 2015 after getting approval from institutional ethical committee. The effective sample size was 171 (assuming an error of margin of $7.5 \%$, the effective sample size came to be 171). ${ }^{9}$ In the present study, the sample size was 200.

\section{Study population}

A total of 200 patients taking NSAIDs, of either sex, of age 18 years and above were included in the study. The following categories of patients were excluded from the study: patients with history of liver or kidney damage, cardiovascular disease, acid peptic diseases, drug allergy, pregnancy and lactation. All the concerned specialist in the department were informed about the aim of the study to seek their cooperation and were assured of full confidentially regarding the patient and treatment information. The data were collected from interviewing the patient and their attendants as well as from patient's case file and recorded in a predesigned, pre-approved patient data sheet.

\section{Data collection tools and method}

All the patients participating in the study were given clear explanations concerning the purpose and nature of the study in a language they understood and written informed consent was obtained before inclusion in the study. Appropriate clinical examination and baseline investigations were done on day 0 . Follow-up examinations were done on $3^{\text {rd }}, 10^{\text {th }}, 30^{\text {th }}$ and $60^{\text {th }}$ day after recruitment. Patient information regarding demographic data, medical history, prescribed treatment details (drug name, dose, frequency, dosage form etc.) and diagnosis were duly recorded on day 0 . ADR were confirmed after consultation with the concerned consultant and simultaneously recorded in detail for each patient. Relevant laboratory investigation values were also noted. Patients were also interviewed for any newly developed ADR during regular follow-up visits.

\section{Duration of data collection}

The documented ADRs were assessed for causality, severity and preventability. Causality assessment which determines the causal relationship of a suspected drug to the ADR in question was done using both WHO-Uppsala Monitoring Centre (WHO-UMC) causality assessment scale10 and Naranjo's algorithm. ${ }^{11}$ WHO-UMC scale divides causality of an ADR into six categories: "certain"; "probable"; "possible"; "unlikely"; "conditional/ unclassified"; and "unassessable/ unclassifiable".

Naranjo's algorithm is a questionnaire which consists of 10 objective questions to assess the causal relationship between the ADR and the suspect drug. There are three options as answers to each question 'yes', 'no' and 'do not know', which are assigned definite mathematical values ($1,0,+1,+2)$ to calculate the total score. The causality is then classified based on the total score as "definite $(\geq 9)$ "; "probable (5-8)"; "possible (1-4)"; and "doubtful (0)".

Modified Hartwig and Siegel scale was used to assess the severity and Modified Schumock and Thornton scale to assess the preventability of the reported ADRs. ${ }^{12,13}$ The modified Hartwig and Siegel scale classifies severity of ADR as "mild," "moderate," and "severe". The modified Schumock and Thornton scale categorizes the preventability of an ADR into "definitely preventable", "probably preventable" and "not preventable".

\section{Statistical analysis}

The data was entered and analysed using Microsoft Office Excel 2010. Presentation of demographics and other numerical data was done using Descriptive statistics (Percentage, Mean \pm Standard Deviation, Tables and Graphs). Association between variables was assessed using Chi-Square test and Fisher's-exact test (Software 
used SPSS version 20). A p-value $<0.05$ was considered significant.

\section{RESULTS}

\section{Demographics}

A total of 227 patients were interviewed and 200 patients were included in the study. The total number of males and females were $92(46 \%)$ and $108(54 \%)$ respectively. Out of a total 200 patients, $156(78 \%)$ were in the $18-64$ years age group with the rest $44(22 \%)$ present in the $\geq 65$ years age group (elderly) (Table 1). The most common analgesic prescribed for acute pain is acelofenac alone or acelofenac+paracetamol. It was used in $44 \%$ of patients with acute pain followed by diclofenac $22.5 \%$ (Table 1 ).

Table 1: Distribution of patient characteristics and drug use indicators.

\begin{tabular}{|ll|}
\hline Variables & $\begin{array}{l}\text { No. of patients } \\
(\mathbf{n = 2 0 0})(\%)\end{array}$ \\
\hline Age (yrs) 18-64 & $156(78)$ \\
\hline$\geq 65$ & $44(22)$ \\
\hline Male & $92(46)$ \\
\hline Female & $108(54)$ \\
\hline $\begin{array}{l}\text { Patients on analgesics from } \\
\text { National list of Essential Medicines } \\
\text { (NLEM) (\%) }\end{array}$ & 71.45 \\
\hline $\begin{array}{l}\text { Patients on analgesics prescribed by } \\
\text { generic name (\%) }\end{array}$ & 56.73 \\
\hline $\begin{array}{l}\text { Patients on NSAIDs co prescribed } \\
\text { with gastroprotecives (\%) }\end{array}$ & 33.4 \\
\hline $\begin{array}{l}\text { Most common analgesic prescribed } \\
\text { in acute pain }\end{array}$ & $\begin{array}{l}\text { Acelofenac (44) } \\
+ \text { paracetamol } \\
88\end{array}$ \\
\hline
\end{tabular}

NLEM national list of essential medicines, NSAIDs nonsteroidal anti-inflammatory drugs

Table 2: Distribution of patients according to the diagnosis.

\begin{tabular}{|ll|}
\hline Diagnosis & $\begin{array}{l}\text { Number of } \\
\text { patients }(\mathbf{n = 2 0 0})\end{array}$ \\
\hline Osteoarthritis of knee/hip & 54 \\
\hline Low backache & 76 \\
\hline Trauma & 6 \\
\hline Neck pain & 22 \\
\hline Bursitis/Tendonitis & 9 \\
\hline Rheumatoid arthritis & 12 \\
\hline Inflammatory & 8 \\
\hline Fracture & 10 \\
\hline Miscellaneous pain disorder & 3 \\
\hline
\end{tabular}

The $2^{\text {nd }}$ column represents the number and percentage of patients who diagnosed with a particular pain disorder.

The most common cause for the prescription of acelofenac was low backache (38\%) followed by osteoarthritis of large joints (27\%) (Table 2). The concomitant drugs most frequently used were calcium-vitamin D (59\%) followed by diacerin-glucosamine $(35 \%)$ and gabapentinmethylcobalamin (32\%) (Table 3). Gastroprotectives drugs were given prophylactically to only those patients who were eligible as per NICE guidelines, rest were given as rescue drugs in the event of development of gastric ADR. ${ }^{14}$

Table 3: Number of patients on concomitant medication.

\begin{tabular}{|ll|}
\hline Concomitant Medication & $\begin{array}{l}\text { No. of patients } \\
\text { (n) }(\%)\end{array}$ \\
\hline Calcium+Vitamin D & $118(59)$ \\
\hline Thiocolchicide & $58(29)$ \\
\hline Pantaprazole & $51(25)$ \\
\hline Antacids & $35(17)$ \\
\hline Gabapentin-Methylcobalamin & $64(32)$ \\
\hline Diacerin-Glucosamine & $60(30)$ \\
\hline Trypsin-bromelain-rutopside & $38(19)$ \\
\hline Collagen peptide & $22(11)$ \\
\hline Deflazacort & $14(7)$ \\
\hline 5\% Lidocaine patch & $5(2)$ \\
\hline Benzodiazepines & $12(6)$ \\
\hline H2-blockers & $26(13)$ \\
\hline Antimicrobials & $13(6)$ \\
\hline Ginkgo biloba & $40(20)$ \\
\hline Ginger/garlic & $12(6)$ \\
\hline
\end{tabular}

The $2^{\text {nd }}$ column represents the number and percentage of patients who were taking additional drugs apart from non-steroidal antiinflammatory drugs

Table 4: Number of patients reported ADRs.

\begin{tabular}{|lll|}
\hline $\begin{array}{l}\text { Suspected } \\
\text { Medication }\end{array}$ & $\begin{array}{l}\text { No. of } \\
\text { patients on } \\
\text { medication } \\
(\mathbf{n = 2 0 0 )}\end{array}$ & $\begin{array}{l}\text { No. of } \\
\text { patients } \\
\text { developed } \\
\text { ADRs n (\%) }\end{array}$ \\
\hline $\begin{array}{l}\text { Acelofenac/acelofen } \\
\text { ac+Paracetamol }\end{array}$ & 88 & $14(16)$ \\
\hline Diclofenac & 45 & $21(47)$ \\
\hline Etoricoxib & 11 & $2(18)$ \\
\hline Ibuprofen & 29 & $6(21)$ \\
\hline Indomethacin & 7 & $1(14)$ \\
\hline Meloxicam & 4 & $1(25)$ \\
\hline Piroxicam & 9 & $4(44)$ \\
\hline Tapentadol & 7 & $2(28)$ \\
\hline
\end{tabular}

The $3^{\text {rd }}$ column represents the number and percentage of patients who developed ADRs on a particular drug

Table 5: Age of patients and ADRs.

\begin{tabular}{|llll|}
\hline $\begin{array}{l}\text { Age group } \\
\text { (yrs) }\end{array}$ & \multicolumn{2}{l|}{ No. of patients n (\%) } & Total \\
\hline & With ADR & Without ADR & \\
\hline $18-64$ & $28(18)$ & $128(82)$ & 156 \\
\hline$\geq 65$ & $23(52)$ & $21(48)$ & 44 \\
\hline
\end{tabular}

ADR adverse drug reaction 


\section{ADRs reporting}

A total of 84 ADRs were reported from 51 (25.5\%) patients enrolled in this study. Maximum number of ADRs were reported in patients on diclofenac $(47 \%)$ followed by piroxicam (44\%) (Table 4).

The incidence of ADRs was higher in the elderly (52\%) than the non-elderly (18\%) (Table 5).
According to the WHO-ART classification most common type of ADRs were reported from GIT followed by skin and autonomic nervous system (Table 6).

\section{Causality, Severity and Preventability Assessment of ADRs}

Causality assessment by both Naranjo's algorithm and WHO- UMC scale classified majority of ADRs as 'probable' followed by 'possible and definite' (Figure 1).

Table 6: Organ system affected due to adverse drug reactions according to the WHO adverse reaction terminology.

\begin{tabular}{|lll|}
\hline SOC (WHO-ART SOC Code) & $\begin{array}{l}\text { \%age of ADRs } \\
(\mathbf{n = 8 4})\end{array}$ & $\begin{array}{l}\text { ADRs (number of patients affected) } \\
\text { a }\end{array}$ \\
\hline Gastrointestinal disorders (0600) & $38(32)$ & $\begin{array}{l}\text { Nausea (14), vomiting (4), dyspepsia (11), diarrhoea (2), } \\
\text { melena (1). }\end{array}$ \\
\hline Skin (0100) & $18(14)$ & Alopecia (2), acne (6), rash (3), itching (2), urticaria (1) \\
\hline Urinary (1300) & $8(8)$ & Difficulty in urination (3), discoloration of urine (5) \\
\hline CNS (0410) & $6(5)$ & Headache (2), tremors (1), sedation (2) \\
\hline ANS (0420) & $12(10)$ & Dizziness (6), dry mouth (4) \\
\hline Musculo-skeletal disorders (0200) & $3(3)$ & Fatigue(3) \\
\hline Psychiatric (0500) & $4(5)$ & Difficulty in concentration (3), increased dream activity (1) \\
\hline Sexual (1400) & $(1)$ & Erectile dysfunction \\
\hline Hepatobillary (0700) & $(1)$ & Jaundice \\
\hline $\begin{array}{l}\text { Metabolic and nutritional disorders } \\
(0800)\end{array}$ & $(2)$ & Weight gain (1), Decreased appetite (1) \\
\hline CVS (1030) & $(1)$ & Palpitations (1) \\
\hline Blood disorders (1200) & $(2)$ & Anaemia (1), epistaxis (1) \\
\hline
\end{tabular}

The $2^{\text {nd }}$ column represents the number and percentage of patients who developed ADRs of a particular organ system The $3^{\text {rd }}$ column represents the number and percentage of patients who experienced the more specific type of ADRs. ADRs adverse drug reactions, WHOART SOC who adverse drug reaction terminology source information a one drug might have contributed to multiple ADR

The association of results with both the scales was highly significant (Fisher's-exact test $\mathrm{p}<0.001$ ).

Table 7: Management of ADRs.

\begin{tabular}{|l|l|}
\hline Interventions & $\begin{array}{l}\text { No. of patients } \\
(\mathbf{n}=\mathbf{5 1})\end{array}$ \\
\hline Dose reduction & 13 \\
\hline Dose reduction and prophylaxis added & 5 \\
\hline Change the medication & 7 \\
\hline $\begin{array}{l}\text { Change the medication and } \\
\text { prophylaxis added }\end{array}$ & 2 \\
\hline $\begin{array}{l}\text { Drug withdrawal and additional } \\
\text { treatment required }\end{array}$ & 1 \\
\hline $\begin{array}{l}\text { Spontaneously recovered during } \\
\text { treatment }\end{array}$ & 6 \\
\hline Nothing is done & 17 \\
\hline
\end{tabular}

ADRs adverse drug reactions

Majority of ADRs were assessed as mild (73.4\%) according to modified Hartwig and Seigel scale. There were $6(5 \%)$ cases of severe or life-threatening ADRs which required hospitalization. Most of the ADRs were assessed to be probably preventable (66.7\%) according to modified Schumock and Thornton scale (Figure 2). The association between gender and severity or preventability of ADR was not statistically significant (Chi-Square test $\mathrm{p}>0.05$ ).

Table 8: Outcome of management of ADRs.

\begin{tabular}{|ll|}
\hline Outcome & Percentage of patients \\
\hline Recovered fully & $56 \%$ \\
\hline Recovered partially & $27 \%$ \\
\hline Unchanged clinical condition & $5 \%$ \\
\hline Hospitalization & $12 \%$ \\
\hline Fatal & $0 \%$ \\
\hline
\end{tabular}

ADRs adverse drug reactions

Most of the ADRs were mild and tolerable; as a result, nothing was done in those cases (33\%). In $35 \%$ of cases either dose was reduced or plus prophylaxis was added. The drug was withdrawal and additional treatment required in only $0.02 \%$ of cases (Table 7 ). None of the 
reaction was fatal. The $60 \%$ of patients were recovered fully on interventions (Table 8).

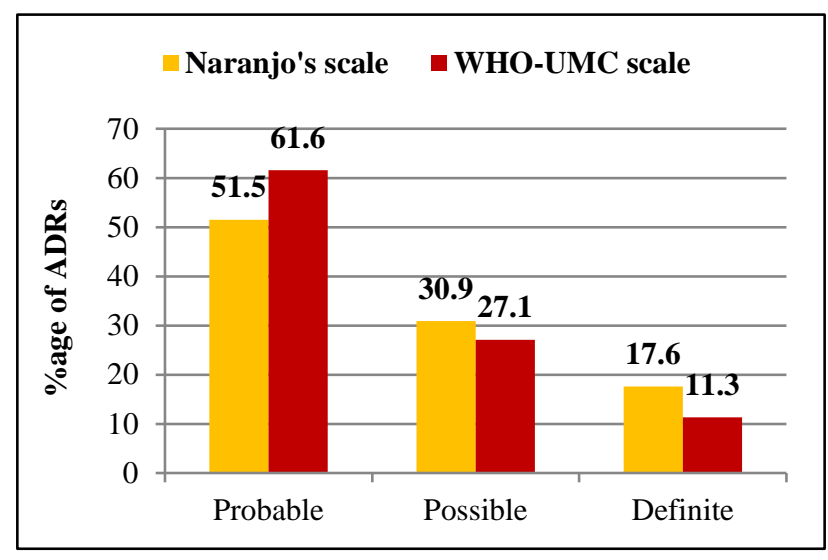

Figure: 1 Causality assessment of ADRs using Naranjo's algorithm and WHO-UMC scale $(n=84)$.

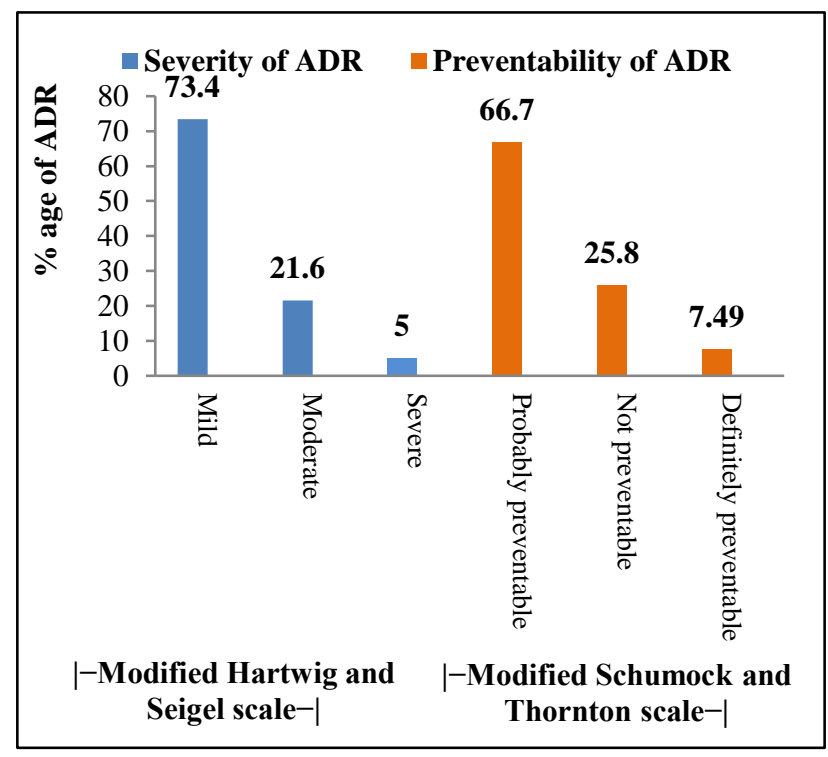

Figure: 2 Severity (Modified Hartwig and Seigel scale) and preventability (Modified Schumock and Thornton scale) assessment $(n=84)$.

\section{DISCUSSION}

This study reveals that most common indication for prescription of analgesics was low backache and acelofenac alone or in combination with paracetamol was the most commonly prescribed drug. Prescribing drugs by generic name, promote rational use of drugs with regard to safety, efficacy and cost of drugs. ${ }^{15}$ In this study, $56.73 \%$ prescriptions were written in generic name. This is quite an encouraging observation but there is need for improvement so as to comply with the WHO standard that all prescriptions must be written in generics.

Globally, NSAIDs are most commonly prescribed drugs for the management of acute pain and inflammation. Despite the wide clinical use of NSAIDs, their gastrointestinal toxicity is the major limitation in clinical use. Hence, they are co-prescribed with gastroprotective agents. ${ }^{16}$ The use of pantaprazole/H2 blockers remain restricted to the patients who developed gastrointestinal symptoms of gastritis or those having past history of such symptoms. Authors found 33\% of NSAIDs being coprescribed with gastroprotectives in present study. Despite of this the incidence of gastritis with diclofenac was $9 \%$, which found to be much higher than USFDA reported $(0.98 \%) .{ }^{17}$ In this study, $71.45 \%$ drugs were prescribed from the National list of Essential Medicines (NLEM), India 2015. ${ }^{18}$ The findings from Sen et al, study showed prescribed drugs from the NLEM (India 2011) were $81.94 \%$, Salman et al, were $62.2 \%$ from NLEM (India 2003). ${ }^{19,20}$

The present study reported a total number of ADRs 84 from 51 patients; indicated few patients developed more than one ADR. There was not a significant difference in the number of the ADRs in relation to the gender. Maximum numbers of ADRs were reported from GIT system (32/84). Out of 32 gastric ADRs, $28(87 \%)$ were in the nongastroprotectives group, whereas $4(13 \%)$ were in the gastroprotectives group $(\mathrm{p}=0.002)$. Present results are in agreement with those of Nidhi et al, who reported $75 \%$ of ADRs from GIT system. ${ }^{21}$ In present study, maximum ADRs were reported by the use of diclofenac (47\%) in acute pain management. Our result correlates with Gor et al, who reported $73 \%$ of ADRs due to diclofenac in his study. ${ }^{22}$

Age is the one of the significant risk factor associated with the occurrence of ADRs. In present study the incidence of ADRs in the elderly was significantly higher than the nonelderly group $(\mathrm{p}=0.006)$. Present study result correlates with the other studies who also found that elderly people were at greater risk of developing ADRs. ${ }^{23,24}$ Though old age is not considered to be factor which can forecast an adverse drug reactions but this is considered to be marker for altered pharmacokinetics, pharmacodynamics, comorbidity and poly-pharmacy. All these factors might be responsible for higher incidence of ADRs in elderly.

In the present study, 27.2\% smokers developed gastrointestinal ADRs as compared to $8.3 \%$ among nonsmokers $(\mathrm{p}=0.01)$. Chronic alcoholism is another factor responsible for higher incidence of ADRs. Authors found that $62.6 \%$ of patients who consumed alcohol developed ADR in comparison to $9.4 \%$ of patients who were nonalcoholic $(\mathrm{p}=0.001)$. These findings are consistent with the results of other studies. ${ }^{25-27}$ Regarding causality assessment, maximum cases were as 'probably' according to both Naranjo and WHO-UMC causality assessment scales. Present study had $17.6 \%$ 'certain' ADR on Naranjo scale, but re-challenge test was not performed by clinician, once the drug was withdrawn.

Most of the reactions were of mild to moderate severity. The reactions which were mild level 1 or 2 were nausea, dizziness, dry mouth, acne and dyspepsia. ADRs such as 
sexual dysfunction, weight gain, jaundice and difficulty in urination were assessed as moderate level 3 or 4 . There were six cases of severe level 5, 6 or 7 ADRs in the present study. All severe cases were required hospitalization. The most common causes of hospitalization were gastric ulcer (4), melena (1) and upper GI bleed (1). In authors' opinion, these results were related, to the severity of ADRs due to inappropriate use of NSAIDs.

In the preventability assessment, $66.7 \%$ ADRs were found to be probably preventable. NSAIDs accounted for $56 \%$ of preventable ADRs while $25.8 \%$ of the ADRs were 'not preventable'. Reactions like vomiting, constipation, dyspepsia and fatigue were 'definitely preventable' and the others such as diarrhoea, weight gain, acne, itching, urticaria were 'probably preventable'. In $43(77 \%)$ out of 56 probably preventable cases, the underlying mechanism of ADRs was dose-related, while in 13 preventable cases the underlying mechanism was susceptibility. The most common reasons detected during these reported ADRs were labeled drug-drug interactions (e.g. NSAIDs + low dose aspirin), therapeutic duplication (e.g. diclofenac + ibuprofen), incorrect duration of treatment, fail to reveal past history of hypersensitivity reactions to drug class and self-medication with herbal or/and over-the-counter drugs.

In patients with GI disturbances, tremors, itching, sedation either the dose was reduced or plus prophylaxis was added. Reactions like alopecia, weight gain, difficulty in urination and decreased appetite were managed with change of drug. The jaundice was detected in a single patient who was on indomethacin; required withdrawal of drug. In present study, none of the ADRs were fatal.

A combination of acelofenac with paracetamol was used commonly when pain was not controlled by acelofenac alone. Both the drugs were given as concomitant therapy and not as a fixed dose combination (FDC). Synergism between paracetamol and an NSAIDs is observed in acute pain. ${ }^{28}$ The WHO pain management module also emphasizes the use of paracetamol as analgesic of first choice and, if pain is not controlled, any other NSAIDs can be added as concomitant therapy. ${ }^{29}$ A positive finding in this study is that no analgesic FDCs were used to treat any patients. In this study $18 \%$ of patients required the use of opioid together with an NSAIDs \pm paracetamol. As compared with NSAIDs, opioids in therapeutic doses relieve pain acting through central mechanisms. They reduce suffering by altering the emotional component of the painful experience, as well as producing a higher degree of analgesia than NSAIDs. ${ }^{30}$ Opioid analgesics are used for extremely painful conditions in authors' orthopedic OPD like non-displaced fracture, hairline fractures and trauma.

Some limitations must be considered. There were chances of missing certain ADRs during the study period since some of them may have been transient or not severe enough to significantly trouble the patient to remember it and report. The study was done in OPD patients only and thus indoor patients were excluded. Also, for logistical reasons, we interviewed the patients only during morning OPD timings from 8.30 am to $12.30 \mathrm{pm}$. So, it is possible that we may have missed some patients who came during the evening OPD. The majority of patients coming to orthopedic department of authors' hospital had already been taking paracetamol at home for immediate pain relief. As paracetamol was providing inadequate pain relief and many patients had inflammatory conditions, antiinflammatory treatment with diclofenac was initiated when patients came to the hospital. None of the analgesics were prescribed as injectable and FDCs. Despite these limitations, this study has identified some encouraging facts that selection of analgesic, prescription by generic, prescription from NLEM, ADRs causality, severity and preventability were appropriate as per WHO pain management guidelines.

\section{CONCLUSION}

Monitoring of ADRs is an ongoing and continuing process. Though pharmacovigilance is still in its infancy in India, this is likely to expand in the times to come. This is because as the newer and newer drugs hit the market, the need for pharmacovigilance grows more than ever before. Pharmacovigilance is an important tool for the treating physician to develop safe medical practice. Identifying the adverse drug events, recording them meticulously and reporting them to the concerned authority is a valuable task in medical profession. This practice will prove to be very valuable in making the drug therapy safer and rational. Such prospective studies conducted across multiple hospitals through active collaboration of orthopedtricians and pharmacologists can be helpful in building up a database for ADRs occurring due to analgesics. This study has paved the way to carry out further studies on a large population in the future.

\section{Funding: No funding sources Conflict of interest: None declared \\ Ethical approval: The study was approved by the Institutional Ethics Committee of Maharishi Markandeshwar University of Medical Sciences (IEC/MMIMSR/16/223)}

\section{REFERENCES}

1. Hartrick CT. Tapentadol immediate release for the relief of moderate-to-severe acute pain. Expert Opin Pharmacother. 2009;16:2687-96.

2. Pattanittum P, Turner T, Green S, Buchbinder R. Nonsteroidal anti-inflammatory drugs (NSAIDs) for treating lateral elbow pain in adults. Cochrane Database Syst Rev. 2013;5:CD003686.

3. Fennerty MB. NSAID-related gastrointestinal injury: evidencebased approach to a preventable complication. Postgrad Med. 2001;110(87-8):91-4.

4. Gautam CS, Saha L. Fixed dose drug combinations (FDCs): rational or irrational: a view point. Br J Clin Pharmacol. 2007;65:795-6. 
5. Chakraborti A. Fixed dose combinations in therapy. Express Pharma. 2007; 2:62-3.

6. Dureja GP, Jain PN, Joshi M, Saxena A, Das G, Ahdal J, et al. Addressing the barriers related with opioid therapy for management of chronic pain in India. Pain Management. 2017 Jul;7(4):311-30.

7. World Health Organization. International drug monitoring: The role of national centres. Report of a WHO meeting. World Health Organ Tech Rep Ser. 1972;498:1-25.

8. World Health Organization (WHO). The Importance of Pharmacovigilance: Safety monitoring of medicinal products. WHO, Geneva, 2002.

9. Naing L, Winn T, Rusli BN. Practical issues in calculating the sample size for prevalence studies. Arch Orofacial Sci. 2006;1:9-14.

10. World Health Organization. Uppsala monitoring centre. Causality assessment of suspected adverse reactions. Available at: http://who-umc. org/Graphics/24734.pdf. Accessed 26 July 2016.

11. Naranjo CA, Busto U, Sellers EM, Sandor P, Ruiz I, Roberts EA, et al. A method for estimating the probability of adverse drug reactions. Clin Pharmacol Therapeut. 1981;30(2):239-45.

12. Hartwig SC, Siegel J, Schneider PJ. Preventability and severity assessment in reporting adverse drug reactions. Am J Health Sys Pharma. 1992 Sep 1;49(9):2229-32.

13. Schumock GT, Thornton JP. Focusing on the preventability of adverse drug reactions. Hospital Pharma. 1992 Jun;27(6):538.

14. Nice guidelines for acute upper gastrointestinal bleeding in over 16s: management. Available at: https://www.nice.org.uk/guidance/cg141. Accessed 26 July 2016.

15. Maheshwari N, Wagh RJ, Chincholkar AS, Gupta M. Prescription pattern monitoring of nonsteroidal antiinflammatory drugs (NSAIDs) in urban health centre in Talegaon. Int J Pharma Bio Sci. 2015;6:596-602.

16. Muraraiah S, Rajarathna K, Vishwanath M, Ramaswamy A, Kamath SD, Seshu S. Evaluation of WHO prescribing indicators among orthopaedic inpatients at a tertiary care hospital. J Chem Pharm Res. 2014;6:278-80.

17. Review: could diclofenac cause gastritis?. Available at: http://www.ehealthme.com/ds/diclofenac? sodium/gastritis. Accessed 14 August 2016.

18. National List of Essential Medicines of India. 2015. Available at: http://www.cdsco.nic.in/forms/Default .aspx. Accessed 26 July2016.

19. Sen S, Bathini P. Auditing analgesic use in postoperative setting in a teaching hospital. JCDR. 2015 Apr;9(4):FC01.

20. Salman MT, Akram MF, Rahman S, Khan FA, Haseen MA, Khan SW. Drug prescribing pattern in surgical wards of a teaching hospital in North India. Indian J e Practising Doctor. 2008;5(2):5-8.

21. Patel NS, Shah RB, Buch JG. Drug utilization pattern of NSAIDs assessed with the anatomical therapeutic chemical classification/defined daily dose system in an orthopedic department. Drugs Therapy Perspectives. 2015 Oct 1;31(10):358-64.

22. Gor AP, Saksena M. Adverse drug reactions of nonsteroidal anti-inflammatory drugs in orthopedic patients. J Pharmacol Pharmacotherapeut. 2011 Jan;2(1):26.

23. De Paepe P, Petrovic M, Outtier L, Van Maele GE, Buylaert W. Drug interactions and adverse drug reactions in the older patients admitted to the emergency department. Acta Clin Belgica. 2013 Feb $1 ; 68(1): 15-21$.

24. Pirmohamed M, Breckenridge AM, Kitteringham NR, Park BK. Adverse drug reactions. BMJ. 1998;316(7140):1295-98.

25. Moore N, Pollack C, Butkerait P. Adverse drug reactions and drug-drug interactions with over-thecounter NSAIDs. Therapeutics Clin Risk Managem. 2015;11:1061.

26. Hameed L, Onyekwere CA, Otegbayo JA, Abdulkareem FB. A clinicopathological study of dyspeptic subjects in Lagos, Nigeria. Gastroenterol Insights. 2012 May 28;4(1):11.

27. Conaghan PG. A turbulent decade for NSAIDs: update on current concepts of classification, epidemiology, comparative efficacy, and toxicity. Rheumatol Int. 2012 Jun 1;32(6):1491-502.

28. Miranda HF, Puig MM, Prieto JC, Pinardi G. Synergism between paracetamol and nonsteroidal anti-inflammatory drugs in experimental acute pain. Pain. 2006 Mar 1;121(1-2):22-8.

29. Tripathi S, Shah R, Sharma DC. Analgesic activity of fixed dose combinations of paracetamol with diclofenac sodium and paracetamol with tramadol on different pain models in healthy volunteers-A randomized double blind crossover study. J Anaesthesiol Clin Pharmacol. 2012 Oct;28(4):465.

30. Dashputra Amruta V. Utilization of analgesics in perioperative cases of teaching hospital. Int $\mathbf{J}$ Med Pharmaceut Sci. 2013;3(6):14-9.

Cite this article as: Sidhu HS, Sadhotra A. Evaluation the pattern of adverse drug reactions by non-steroidal anti-inflammatory drugs at the outpatient orthopedics department of a university teaching hospital in north India. Int J Basic Clin Pharmacol 2018;7:1974-80. 